\title{
Food sources and correlates of sodium and potassium intakes in Flemish pre-school children
}

\author{
Inge Huybrechts ${ }^{1, *}$, Willem De Keyzer ${ }^{1,2}, Y_{i}$ Lin $^{1}$, Stefanie Vandevijvere ${ }^{3}$, \\ Carine Vereecken ${ }^{1}$, Herman Van Oyen ${ }^{3}$, Katrien Tilleman ${ }^{4}$, Mia Bellemans ${ }^{1}$, \\ Mieke De Maeyer ${ }^{\prime}$, Guy De Backer ${ }^{1}$ and Stefaan De Henauw ${ }^{1,2}$ \\ 'Department of Public Health, Faculty of Medicine and Health Sciences, Ghent University, UZ - 2 Blok A, \\ De Pintelaan 185, B-9000 Ghent, Belgium: ${ }^{2}$ Department of Nutrition and Dietetics, University College Ghent, \\ Ghent, Belgium: ${ }^{3}$ Unit of Epidemiology, Scientific Institute of Public Health, Brussels, Belgium: ${ }^{4}$ Faculty of \\ Medicine and Health Sciences, Ghent University, Ghent, Belgium
}

Submitted 4 December 2010: Accepted 8 September 2011: First published online 6 0ctober 2011

\begin{abstract}
Objective: The aim of the present study was to investigate dietary sources of $\mathrm{Na}$ and $\mathrm{K}$ intakes among Flemish pre-school children using multiple linear regression analyses.

Design: Three-day estimated diet records were used to assess dietary intakes. The contribution to $\mathrm{Na}$ and $\mathrm{K}$ intakes of fifty-seven food groups was computed by summing the amount provided by the food group for all individuals divided by the total intake for all individuals.

Setting: A random cluster sampling design at the level of schools, stratified by province and age, was used.

Subjects: A representative sample of 696 Flemish pre-school children aged $2 \cdot 5-6 \cdot 5$ years was recruited.

Results: Mean $\mathrm{Na}$ intake was above and mean $\mathrm{K}$ intake was largely below the recommendation for children. Bread (22\%) and soup (13\%) were main contributors to $\mathrm{Na}$ intake followed by cold meat cuts and other meat products $(12 \%$ and $11 \%$, respectively). Sugared milk drinks, fried potatoes, milk and fruit juices were the main K sources (13\%, 12\%, 11\% and 11\%, respectively). Although Na and $\mathrm{K}$ intakes were positively correlated, several food categories showed Na:K intake ratio well above one (water, cheeses, soup, butter/margarine, fast foods and light beverages) whereas others presented a ratio well below one (oil \& fat, fruits \& juices, potatoes, vegetables and hot beverages).

Conclusions: Flemish pre-school children had too high $\mathrm{Na}$ and too low $\mathrm{K}$ intakes. The finding that main dietary sources of $\mathrm{Na}$ and $\mathrm{K}$ are clearly different indicates the feasibility of simultaneously decreasing $\mathrm{Na}$ and increasing $\mathrm{K}$ intake among children.
\end{abstract}

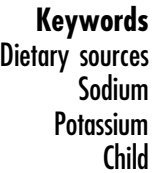

A large number of studies indicate that elevated blood pressure, which may lead to stroke, CHD and kidney disease, is associated with increased $\mathrm{Na}$ and inadequate $\mathrm{K}$ intakes ${ }^{(1-3)}$. In addition, some research has reported increased risks for gastric cancer with higher salt intake ${ }^{(4)}$. Although most studies have focused on health effects in adults, more recently it was shown that a modest salt reduction in children also causes an immediate fall in blood pressure and, if continued, may lessen the subsequent rise in blood pressure with age ${ }^{(5-7)}$. As demonstrated by Wang and colleagues, children are likely to maintain their dietary intake patterns from childhood into adolescence (the 'tracking' phenomenon) ${ }^{(8)}$. Therefore, children with high salt intakes are likely to consume high amounts of salt in adulthood, which increases their risks for hypertension and CVD in adulthood.

Epidemiological studies also suggest that higher levels of $\mathrm{K}$ intake from foods are associated with decreased bone $\operatorname{loss}^{(9)}$. Furthermore, evidence shows the important role of $\mathrm{K}$ intake in regulating blood pressure and other beneficial effects of $\mathrm{K}$ which may be independent of and additional to its effect on blood pressure ${ }^{(1,3,10-12)}$. It is important to note that the beneficial effects of $\mathrm{K}$ in these studies appear to be mainly from the forms of $\mathrm{K}$ that are associated with bicarbonate precursors, the forms found naturally in foods such as fruits and vegetables ${ }^{(1)}$.

Previous results on intakes of $\mathrm{Na}$ and $\mathrm{K}$ among Flemish pre-school children revealed that more than three-quarters 
of the children younger than 4 years old and more than $40 \%$ of the children at least 4 years old exceeded the Upper Level (UL) for $\mathrm{Na}$ recommended by the Institute of Medicine $(\mathrm{IOM})^{(13)}$. Furthermore, more than threequarters of the children did not reach the IOM's recommended Adequate Intake (AI) for $\mathrm{K}^{(13)}$.

Consequently, these increased $\mathrm{Na}$ and inadequate $\mathrm{K}$ intakes, in comparison with the IOM recommendations, are cause for concern for the health of Belgian pre-school children. Therefore, it is important to investigate what food sources are contributing most to the daily total $\mathrm{Na}$ and $\mathrm{K}$ intakes among Flemish pre-school children.

The present study analyses a dietary survey that was performed among Flemish pre-school children, and aims to identify their main food sources of $\mathrm{Na}$ and $\mathrm{K}$ intakes. The ratio of $\mathrm{Na}$ to $\mathrm{K}$ in the pre-school children's dietary intakes was also investigated since the dietary $\mathrm{Na}: \mathrm{K}$ intake ratio is related to the rise in blood pressure in childhood and may be important in the early pathogenesis of primary hypertension $^{(11)}$.

\section{Methods}

\section{Survey population}

The present study used data from the Flanders pre-school dietary survey (data collected from October 2002 until February 2003), in which usual dietary intake was estimated from $3 \mathrm{~d}$ estimated dietary records (3d EDR) and an FFQ with forty-seven food items, completed by a proxy (the parents or a caregiver). The Flanders pre-school dietary survey is the only large-scale dietary survey conducted in Flanders that included all the different Flemish provinces and in which the number of children participating in the survey was proportional to the total number of children living in each province. A multistage stratified random cluster design was used, with schools as primary sampling units and classes as secondary sampling units (stratified per province). In total, sixty-five nursery schools had to be selected (randomly per province) from lists made available by the Flemish Ministry of Education and Training, in order to achieve our study aim of fifty nursery schools spread all over Flanders. Although willingness to participate in a survey leads to some selection bias, the data obtained in this survey represent a more general population of pre-school children in Flanders compared with other food consumption surveys in the past which were restricted to local areas. The sampling design, methods, representativeness and response rate (50\% response rate and $49 \%$ after data cleaning) have been described in detail previously ${ }^{(14)}$.

The percentage of under-reporters was calculated using the individual Goldberg cut-offs ${ }^{(15)}$ (adapted for children) and has been described in depth in a previous paper where the under-reporting was shown to be low $(<2 \% \text { of the children })^{(13)}$. Under-reporters have not been excluded from the study sample that was used for the analyses reported in the present paper.

The Ethical Committee of the Ghent University Hospital (Belgium) granted ethical approval for the study. Informed written consent was obtained from all parents.

\section{Assessment of dietary $N a$ and $K$ intakes}

For the current analyses, only food diaries including three completed record days were included. After exclusion of diaries that included only one or two complete record days, a final sample of 696 (66\% of collected) diaries was left for the statistical analyses. A record day was considered complete if at least two meals were recorded. Two dietitians, with long-standing experience in nutritional epidemiological fieldwork, performed the EDR exclusion procedure.

The food composition data for calculating nutrients were based on the following tables: the Belgian food composition table NUBEL ${ }^{(16)}$, the Dutch food composition database $\mathrm{NEVO}^{(17)}$, the food composition table of the Belgian Institute Paul Lambin ${ }^{(18)}$ and McCance and Widdowson's UK food composition table ${ }^{(19)}$. Loss of vitamins and minerals during preparations were taken into account as all relevant foods were coded 'as eaten' and not 'as raw'.

In total 936 foods and composite dishes were encoded in the original database. All recipes that were described in depth as ingredients in the diaries were encoded as ingredients in the original database. After the disaggregating procedures, food items and ingredients were divided into fifty-seven food groups of similar nutrient content based on the classification of the Flemish food-based dietary guidelines and the expert opinion of the investigators (see food groups listed in Table 3).

As mentioned before, discretionary salt has not been included in the current analyses since use of salt was seldom reported and/or quantified in the diaries.

\section{Statistical analyses}

The SPSS for Windows statistical software package version 14 (SPSS Inc., Chicago, IL, USA) was used to perform statistical analyses.

Mean and median 'usual' intakes of the population, and the proportion below or above defined cut-offs, were calculated using statistical modelling (using the Software for Intake Distribution Estimation, C-SIDE; Iowa State University, Ames, IA, USA ${ }^{(20)}$ ) in order to correct for day-today variability in the $3 \mathrm{~d}$ EDR. Since the recommendations of the IOM try to consider health benefits of increased $\mathrm{K}$ levels higher than the minimal needs for losses and growth as well, these Dietary Reference Intakes (DRI) from the IOM were used to compare with the total $\mathrm{Na}$ and $\mathrm{K}$ intakes ${ }^{(1,21)}$.

Dietary sources of $\mathrm{Na}$ and $\mathrm{K}$ were evaluated through the fifty-seven food and beverage categories that were constituted by grouping items with similar characteristics. The population proportion formula was used to determine the percentage contribution of each of the fifty-seven 
Table 1 Distributions of sodium and potassium intakes and of their ratio among Flemish pre-school children $(n 696)$ aged $2 \cdot 5-6 \cdot 5$ years, Flanders pre-school dietary survey, 2002-2003

\begin{tabular}{|c|c|c|c|c|c|c|c|c|c|c|c|c|}
\hline \multirow[b]{2}{*}{ Nutrient intake* $^{*}$} & \multicolumn{3}{|c|}{ Dietary recommendations } & \multirow[b]{2}{*}{ Mean } & \multirow[b]{2}{*}{$95 \% \mathrm{Cl}$} & \multirow[b]{2}{*}{ Min } & \multicolumn{5}{|c|}{ Percentile } & \multirow[b]{2}{*}{$\operatorname{Max}$} \\
\hline & Belgian SHC (AR) & $\mathrm{IOM}(\mathrm{Al})$ & IOM (UL) & & & & 10th & 25th & 50th & 75th & 90th & \\
\hline \multicolumn{13}{|c|}{ Total population ( $n$ 696) } \\
\hline $\mathrm{Na}(\mathrm{mg} / \mathrm{d})$ & & & & 1872 & 1833, 1911 & 623 & 1280 & 1498 & 1822 & 2174 & 2560 & 5591 \\
\hline $\mathrm{K}(\mathrm{mg} / \mathrm{d})$ & & & & 2381 & 2337,2425 & 910 & 1672 & 1979 & 2327 & 2717 & 3148 & 5499 \\
\hline Na:K ratio & & & & $0 \cdot 81$ & $0 \cdot 80,0 \cdot 83$ & 0.27 & 0.54 & 0.64 & 0.78 & 0.93 & $1 \cdot 14$ & $2 \cdot 65$ \\
\hline \multicolumn{13}{|c|}{ Children 2-3 years $(n$ 197) $\dagger$} \\
\hline $\mathrm{Na}(\mathrm{mg} / \mathrm{d})$ & $225-500$ & 1000 & 1500 & 1758 & 1689,1828 & 623 & 1225 & 1387 & 1710 & 2035 & 2498 & 3400 \\
\hline $\mathrm{K}(\mathrm{mg} / \mathrm{d})$ & $800-1000$ & 3000 & NA & 2322 & 2235,2409 & 933 & 1625 & 1900 & 2263 & 2659 & 3058 & 5499 \\
\hline $\mathrm{Na}: \mathrm{K}$ ratio & & & & $0 \cdot 78$ & $0.75,0.82$ & $0 \cdot 27$ & 0.53 & 0.63 & 0.76 & 0.89 & $1 \cdot 11$ & $1 \cdot 60$ \\
\hline \multicolumn{13}{|c|}{ Children $4-6$ years $(n$ 465) $\dagger$} \\
\hline $\mathrm{Na}(\mathrm{mg} / \mathrm{d})$ & $300-700$ & 1200 & 1900 & 1919 & 1870,1967 & 650 & 1322 & 1536 & 1851 & 2211 & 2615 & 5591 \\
\hline $\mathrm{K}(\mathrm{mg} / \mathrm{d})$ & $1100-1400$ & 3800 & NA & 2405 & 2351,2458 & 910 & 1695 & 2004 & 2358 & 2745 & 3184 & 4581 \\
\hline Na:K ratio & & & & $0 \cdot 83$ & $0.80,0.85$ & 0.33 & 0.55 & 0.64 & 0.79 & 0.96 & $1 \cdot 19$ & $2 \cdot 65$ \\
\hline
\end{tabular}

SHC, Superior Health Council; AR, Acceptable Range; IOM, Institute of Medicine; AI, Adequate Intake; UL, Upper Level; NA, not applicable.

*Distribution was corrected for within-person variability and for day of the week using C-SIDE ${ }^{(20)}$.

tBecause the birth date and age were missing for thirty-four children, the sum of the children included in the two age groups is only 662 instead of 696.

food groups to the intake of $\mathrm{Na}$ and $\mathrm{K}$. This was done by summing the amount of the component provided by the food for all individuals divided by the total intake of that component from all foods for the entire study population $^{(22)}$.

Pearson's correlation coefficients and partial correlation coefficients adjusted for age were computed to test the associations between $\mathrm{Na}$ and $\mathrm{K}$ intakes and total energy intake. Linear regression analyses (univariate) were used to investigate the associations of $\mathrm{Na}$ and $\mathrm{K}$ intakes with the behavioural and sociodemographic variables available in the survey: total energy intake, sex, age, perceived family income as sufficient to provide a healthy diet (yes, perceived as sufficient; most of the time perceived as sufficient; most of the time perceived as insufficient; no, perceived as insufficient), household size ( $\leq 2$ or $>2$ children), occupational status (employed or unemployed), educational level (lower secondary, secondary or higher education) and smoking (currently smoking: yes/no) of the parents, and relevant interactions. In a second step, the significant variables (according to the univariate analysis) were combined in the final model using multiple linear regression analyses. All statistical analyses were tested with a significance level set at $P<0 \cdot 05$.

\section{Results}

\section{Overall distributions of $\mathrm{Na}$ and $\mathrm{K}$ intakes and their ratio}

The minimum and maximum values and percentiles of $\mathrm{Na}$ and $\mathrm{K}$ intakes and of their ratio are reported in Table 1. Mean Na intake was 1872 (95\% CI 1833, 1911) mg/d, mean K intake was 2381 (95\% CI 2337, 2425) mg/d and the mean $\mathrm{Na}: \mathrm{K}$ intake ratio was $0 \cdot 81$ (95\% CI 0•80, 0.83).

In total, $57 \%$ of the children exceeded the IOM's UL for $\mathrm{Na}$ intake of $1500 \mathrm{mg}$ and $1900 \mathrm{mg}$ for children younger
Table 2 Correlations between sodium and potassium intakes and total energy intake among Flemish pre-school children $(n 696)$ aged 2.5-6.5 years, Flanders pre-school dietary survey, 2002-2003

\begin{tabular}{lcccc}
\hline Pearson correlation & $r$ & $P$ & $r^{*}$ & $P^{*}$ \\
\hline $\mathrm{Na}(\mathrm{mg}) \times \mathrm{K}(\mathrm{mg})$ intake & 0.406 & $<0.0001$ & 0.401 & $<0.0001$ \\
Energy $\times \mathrm{Na}(\mathrm{mg})$ intake & 0.575 & $<0.0001$ & 0.566 & $<0.0001$ \\
Energy $\times \mathrm{K}(\mathrm{mg})$ intake & 0.695 & $<0.0001$ & 0.711 & $<0.0001$ \\
$\mathrm{Na}(\mathrm{mg} / 4184 \mathrm{~kJ}(1000 \mathrm{kcal})) \times$ & 0.038 & 0.332 & 0.041 & 0.287 \\
$\mathrm{~K}(\mathrm{mg} / 4184 \mathrm{~kJ}(1000 \mathrm{kcal}))$ & & & & \\
\hline
\end{tabular}

*Adjusted for age, using partial correlations.

than 4 years old and children at least 4 years old, respectively. Ninety-four per cent of the children had a $\mathrm{K}$ intake lower than the IOM's AI value $3000 \mathrm{mg}$ and $3800 \mathrm{mg}$ for children younger than 4 years old and children at least 4 years old, respectively) ${ }^{(1)}$.

\section{Correlations between Na and $\mathrm{K}$ intakes and total energy intake}

As shown in Table 2, $\mathrm{Na}$ and $\mathrm{K}$ intakes were positively correlated with each other and with total energy intake. These correlations were also observed after adjustment for age.

\section{Dietary sources of $\mathrm{Na}$ and $\mathrm{K}$}

Table 3 lists food and beverage groups with their relative contributions to daily $\mathrm{Na}$ and $\mathrm{K}$ intakes in pre-school children. Bread (22\%) and soups (13\%) were the main contributors to $\mathrm{Na}$ intake followed by cold cuts (from meat products) and other meat and meat products (12\% and $11 \%$, respectively). Sugared milk drinks, fried potatoes, milk and fruit juices were the main sources of $\mathrm{K}$ intake (13\%, 12\%, 11\%, and $11 \%$, respectively).

Although $\mathrm{Na}$ and $\mathrm{K}$ intakes were positively correlated to each other and to total energy intake (Table 2), several food categories showed an Na:K intake ratio well above one (olives, water, cheeses, soups, butter/margarine, 
Table 3 Dietary sources of sodium and potassium among Flemish pre-school children $(n 696)$ aged $2 \cdot 5-6 \cdot 5$ years, Flanders pre-school dietary survey, 2002-2003

\begin{tabular}{|c|c|c|c|c|c|c|}
\hline \multirow[b]{2}{*}{ Food group } & \multicolumn{2}{|c|}{ Food intake $(\mathrm{g} / \mathrm{d})$} & \multicolumn{2}{|c|}{$\mathrm{Na}$} & \multicolumn{2}{|c|}{$\mathrm{K}$} \\
\hline & Mean & SD & $\%$ & Order & $\%$ & Order \\
\hline Beverages (incl. juices but no drinks from Restgroup) & $486 \cdot 2$ & & $13 \cdot 8$ & & $13 \cdot 3$ & \\
\hline Water & $224 \cdot 2$ & $226 \cdot 4$ & $0 \cdot 3$ & & 0 & \\
\hline Light beverages & $23 \cdot 1$ & $90 \cdot 1$ & $0 \cdot 1$ & & 0 & \\
\hline Tea and coffee without sugar & $8 \cdot 2$ & $43 \cdot 5$ & 0 & & $0 \cdot 1$ & \\
\hline Fruit juice & $172 \cdot 8$ & $209 \cdot 3$ & $0 \cdot 3$ & & $11 \cdot 3$ & 4 \\
\hline Vegetable juice & 0.2 & $6 \cdot 0$ & 0 & & 0 & \\
\hline Soup/bouillon & $57 \cdot 7$ & $101 \cdot 7$ & $13 \cdot 1$ & 2 & $1 \cdot 8$ & \\
\hline Bread and cereals & $86 \cdot 7$ & & $26 \cdot 6$ & & $6 \cdot 5$ & \\
\hline Bread/rolls/crackers/rice cakes & $70 \cdot 3$ & $46 \cdot 8$ & $22 \cdot 0$ & 1 & $5 \cdot 2$ & 8 \\
\hline Sugared bread & $7 \cdot 5$ & $22 \cdot 5$ & $2 \cdot 0$ & & 0.5 & \\
\hline Breakfast cereals (ready-to-eat/hot) & $8 \cdot 9$ & $20 \cdot 0$ & $2 \cdot 6$ & 10 & 0.8 & \\
\hline Potatoes and grains & $87 \cdot 2$ & & 0.4 & & $11 \cdot 7$ & \\
\hline Pasta/noodles & $15 \cdot 4$ & $41 \cdot 0$ & 0 & & $0 \cdot 1$ & \\
\hline Rice & $6 \cdot 3$ & $25 \cdot 5$ & 0 & & $0 \cdot 1$ & \\
\hline Potatoes & $65 \cdot 0$ & $69 \cdot 3$ & 0.4 & & $11 \cdot 5$ & 2 \\
\hline Vegetables (excluding soup) & $66 \cdot 5$ & & $1 \cdot 7$ & & $7 \cdot 1$ & \\
\hline Cooked vegetables & $53 \cdot 7$ & $60 \cdot 1$ & 1.6 & & $5 \cdot 8$ & 6 \\
\hline Raw vegetables & $12 \cdot 8$ & $38 \cdot 3$ & $0 \cdot 1$ & & $1 \cdot 3$ & \\
\hline Fruit (sweetened/unsweetened) & $109 \cdot 8$ & & $0 \cdot 2$ & & $8 \cdot 3$ & \\
\hline Fresh fruit & $94 \cdot 0$ & $102 \cdot 7$ & $0 \cdot 1$ & & $7 \cdot 5$ & 5 \\
\hline Canned fruit & $15 \cdot 4$ & $45 \cdot 4$ & $0 \cdot 1$ & & 0.6 & \\
\hline Dried fruit & 0.4 & 3.7 & 0 & & $0 \cdot 1$ & \\
\hline Milk, milk products and Ca-enriched soya milk & $439 \cdot 9$ & & $11 \cdot 5$ & & $28 \cdot 1$ & \\
\hline Milk* & $179 \cdot 0$ & $218 \cdot 5$ & $4 \cdot 7$ & 7 & $11 \cdot 3$ & 3 \\
\hline Sugared milk drinks (e.g. Fristi, chocolate milk) & $188 \cdot 3$ & $226 \cdot 8$ & $4 \cdot 4$ & 8 & $12 \cdot 6$ & 1 \\
\hline Yoghurt & 4.5 & $25 \cdot 3$ & 0.2 & & 0.4 & \\
\hline Sugared or aromatized yoghurt & $14 \cdot 2$ & $46 \cdot 9$ & 0.4 & & $1 \cdot 0$ & \\
\hline Soya drinks & $15 \cdot 7$ & $82 \cdot 5$ & 0.5 & & 0.6 & \\
\hline Milk desserts & $19 \cdot 9$ & $56 \cdot 2$ & $0 \cdot 7$ & & $1 \cdot 1$ & \\
\hline Milk desserts based on soya & $2 \cdot 3$ & $19 \cdot 1$ & $0 \cdot 1$ & & $0 \cdot 1$ & \\
\hline Probiotics (e.g. Actimel, Yakult) & $0 \cdot 7$ & $7 \cdot 4$ & 0 & & 0 & \\
\hline White (fresh) cheese & $15 \cdot 3$ & $43 \cdot 3$ & $0 \cdot 4$ & & $1 \cdot 0$ & \\
\hline Cheese & $14 \cdot 5$ & & $6 \cdot 5$ & & 0.6 & \\
\hline Hard cheeset & $11 \cdot 8$ & $22 \cdot 6$ & $5 \cdot 1$ & 5 & 0.4 & \\
\hline Cheese spread & $2 \cdot 7$ & $8 \cdot 8$ & $1 \cdot 4$ & & 0.2 & \\
\hline Fat and oil¥ & $8 \cdot 6$ & & 0.9 & & $0 \cdot 1$ & \\
\hline Butter/margarine & $8 \cdot 3$ & $9 \cdot 5$ & 0.9 & & $0 \cdot 1$ & \\
\hline Oil & 0.3 & $1 \cdot 4$ & 0 & & 0 & \\
\hline Frying oil & 0.0 & 0.6 & 0 & & 0 & \\
\hline Meat/poultry/fish/egg/meat substitutes & $90 \cdot 3$ & & $26 \cdot 1$ & & $11 \cdot 6$ & \\
\hline Meat, game and meat products & $37 \cdot 2$ & $46 \cdot 1$ & $11 \cdot 2$ & 4 & $5 \cdot 3$ & 7 \\
\hline Chicken/turkey & $15 \cdot 9$ & $34 \cdot 7$ & 0.8 & & $2 \cdot 2$ & \\
\hline Fish/shellfish & 8.5 & $28 \cdot 7$ & $1 \cdot 3$ & & $1 \cdot 0$ & \\
\hline Cold cuts (from meat products) & $20 \cdot 7$ & $30 \cdot 2$ & $11 \cdot 7$ & 3 & $2 \cdot 4$ & \\
\hline Cold cuts (from fish products) & 0.9 & $6 \cdot 8$ & 0.3 & & $0 \cdot 1$ & \\
\hline Eggs\& & $5 \cdot 1$ & $18 \cdot 2$ & 0.4 & & 0.3 & \\
\hline Meat substitutes (e.g. tofu, tempe) & $1 \cdot 7$ & 11.6 & 0.3 & & 0.3 & \\
\hline Nuts and seeds & 0.3 & $3 \cdot 4$ & 0 & & 0.1 & \\
\hline Restgroup (snacks and desserts) & $201 \cdot 8$ & & $11 \cdot 1$ & & $12 \cdot 2$ & \\
\hline Brioches & 3.5 & $17 \cdot 0$ & 0.9 & & 0.2 & \\
\hline Sweet snacks & $43 \cdot 6$ & $43 \cdot 5$ & 5 & 6 & $2 \cdot 7$ & 10 \\
\hline Savoury snacks & $2 \cdot 1$ & $9 \cdot 8$ & 0.6 & & $0 \cdot 8$ & \\
\hline Tea and coffee with sugar & $3 \cdot 2$ & $26 \cdot 6$ & 0 & & 0 & \\
\hline Soft drinks & $97 \cdot 7$ & $169 \cdot 4$ & $0 \cdot 2$ & & $0 \cdot 2$ & \\
\hline Savoury sauces & $12 \cdot 5$ & $24 \cdot 9$ & $2 \cdot 6$ & 9 & $1 \cdot 0$ & \\
\hline Cream & 0.3 & $2 \cdot 6$ & 0 & & 0 & \\
\hline Sweet sauces & $0 \cdot 1$ & $2 \cdot 5$ & 0 & & 0 & \\
\hline Chocolate & $3 \cdot 1$ & $9 \cdot 5$ & $0 \cdot 2$ & & 0.5 & \\
\hline Chocolate spread & $9 \cdot 4$ & $13 \cdot 9$ & 0.3 & & $1 \cdot 7$ & \\
\hline Other sweet spread (e.g. jam, honey) & $5 \cdot 3$ & $11 \cdot 6$ & $0 \cdot 1$ & & 0.2 & \\
\hline $\begin{array}{l}\text { Sugar } \\
\text { Sull }\end{array}$ & $0 \cdot 1$ & 0.9 & 0 & & 0 & \\
\hline Fried snacks & 0.1 & $2 \cdot 6$ & 0 & & 0 & \\
\hline French fries/croquettes & $14 \cdot 6$ & $37 \cdot 7$ & 0.9 & & $4 \cdot 3$ & 9 \\
\hline Sweet desserts (e.g. ice cream, tiramisu) & $6 \cdot 2$ & $23 \cdot 2$ & 0.3 & & $0 \cdot 4$ & \\
\hline Miscellaneous & $4 \cdot 3$ & & $1 \cdot 2$ & & $0 \cdot 3$ & \\
\hline Olives & $0 \cdot 1$ & $1 \cdot 5$ & $0 \cdot 1$ & & 0 & \\
\hline Pizza and quiches & $2 \cdot 2$ & $17 \cdot 8$ & $0 \cdot 7$ & & $0 \cdot 2$ & \\
\hline Other miscellaneous $\|$ & $2 \cdot 0$ & $21 \cdot 3$ & 0.5 & & 0.2 & \\
\hline
\end{tabular}

The contributions of each food group are expressed in percentage of daily $\mathrm{Na}$ and $\mathrm{K}$ intakes. The Na: $\mathrm{K}$ intake ratio is the ratio between the daily amounts of $\mathrm{Na}$ and $\mathrm{K}$ provided by each food category.

*Includes cow's milk and goat's milk.

tExcludes cream cheese.

flncludes lard/animal fats and regular/low-fat/fat-free versions of cream cheese/sour cream/half-and-half.

§Includes only eggs reported separately and eggs included in disaggregated food mixtures.

IIIncludes foods or components with negligible contributions to total nutrient intake that could not be categorized in the above food groups (e.g. herbs and spices (including mixtures that include salt)/monosodium glutamate/starch/plain gelatine/artificial sweeteners/pectin/cocoa powder/etc.). 
fast foods and light beverages), whereas others presented a ratio well below one (oil \& fat, fruits \& juices, potatoes, vegetables and hot beverages; Table 3).

\section{Associations of Na and K intakes with other covariates}

No associations were found between $\mathrm{Na}$ and $\mathrm{K}$ intakes and socio-economic status (SES) and lifestyle factors when using the univariate regression analysis. However, a positive association was found between energy intake and both $\mathrm{Na}$ and $\mathrm{K}$ intakes $(\beta=1 \cdot 004, P<0 \cdot 001 ; \beta=1 \cdot 402$, $P<0 \cdot 001$, respectively). With an increase in energy intake of $4 \cdot 184 \mathrm{~kJ}(1 \mathrm{kcal}), \mathrm{Na}$ and $\mathrm{K}$ intakes increased by $1 \cdot 004$ and $1 \cdot 402 \mathrm{mg}$, respectively.

\section{Discussion}

\section{Main results}

The dietary survey performed in 2002 and 2003 among Flemish pre-school children provided us with information on $\mathrm{Na}$ and $\mathrm{K}$ intakes among the children and about the main food sources contributing to these daily intakes. Mean $\mathrm{Na}$ intake was well above, whereas mean $\mathrm{K}$ intake was largely below, the current DRI recommendations in children. The mean Na:K intake ratio for the total population was below one. $\mathrm{Na}$ and $\mathrm{K}$ intakes were both positively associated with energy intake, while most of the other participant characteristics such as parental occupational status and educational level, perceived family income and size were not associated with $\mathrm{Na}$ and $\mathrm{K}$ intakes. This finding suggests that food habits are relatively uniform across the social categories with respect to $\mathrm{Na}$ or $\mathrm{K}$ intake.

Differences could be found between foods included in the same food group, suggesting that recommendations to lower $\mathrm{Na}$ intake should be rather on a more detailed food item level than on a large food group level.

\section{Comparison with the literature}

Although our results correspond well with other studies investigating $\mathrm{Na}$ and $\mathrm{K}$ intakes and their most important food sources among children ${ }^{(23-27)}$, some interesting differences were also found. An important finding was the fact that our $\mathrm{Na}: \mathrm{K}$ intake ratio is less than half that found in French children ${ }^{(26)}$. This lower ratio is mainly explained by lower $\mathrm{Na}$ intake in our Flemish pre-school children. In both surveys, table salt was not included in the analysis. Although differences in food grouping made it difficult to compare our food contributions to $\mathrm{Na}$ and $\mathrm{K}$ intakes with the results derived from French children ${ }^{(26)}$, some interesting differences in food contributors could be found when aggregating some of the food groups. The main differences were found for dairy and meat products, for which the contributions to $\mathrm{Na}$ intake were respectively $12 \%$ and $26 \%$ in Flemish pre-school children and $7 \%$ and $19 \%$ among French children. It is also worth mentioning that the age range of the children in the French study (2-14 years old) was much larger than in our study (2.5-6.5 years old). When comparing the ranking of food groups in the contribution to $\mathrm{Na}$ and $\mathrm{K}$ intakes with other studies, we observed very similar results. Bread, soup and meat products were the major sources of $\mathrm{Na}$, whereas vegetables (when including potatoes), dairy products and fruit (juices) were the major providers of $\mathrm{K}$, similarly to what has been described in other industrialized populations ${ }^{(23-27)}$. Although the contribution from water to total $\mathrm{Na}$ intake was not analysed in the previous surveys mentioned, it should be noted that also water can contribute to total Na intake. While most of the Na contents of the different water types consumed in Belgium were below $20 \mathrm{mg} / \mathrm{l}$, for some water types the $\mathrm{Na}$ level was higher than $20 \mathrm{mg} / 1$ (e.g. Gerolsteiner and Tönissteiner; data not shown).

Similar to the findings of Meneton and colleagues, several food categories showed an $\mathrm{Na}: \mathrm{K}$ intake ratio well above one (cheeses, bread, breakfast cereals and soups) whereas others presented a ratio well below one (fruits (excluding olives), vegetables, dairy products and hot beverages) ${ }^{(26)}$. Thus, despite the strong positive correlation between $\mathrm{Na}$ and $\mathrm{K}$ intakes at the population level, the main dietary sources of $\mathrm{Na}$ and $\mathrm{K}$ were, for the most part, not the same. This emphasizes the feasibility of increasing the consumption of K-rich foods while reducing that of Na-rich foods at the individual level.

Our finding that some participant characteristics such as perceived family income and size were not associated with $\mathrm{Na}$ and $\mathrm{K}$ intakes and their ratio compared well with the results derived from French children ${ }^{(26)}$ and suggests that food habits are relatively uniform across the social categories with respect to $\mathrm{Na}$ or $\mathrm{K}$ intake. However, this finding is in contrast to what has been described in other countries $^{(28-31)}$. It is noteworthy that the lack of information on discretionary salt could bias this conclusion as there might be differences in the use of discretionary salt between different socio-economic classes.

The strong positive correlation between $\mathrm{Na}$ and $\mathrm{K}$ intakes can be explained by the ubiquitous nature of $\mathrm{K}$ that is naturally present in most foods and by the widespread use of $\mathrm{Na}$ in processed foods ${ }^{(32)}$. Thus the main determinant of $\mathrm{Na}$ and $\mathrm{K}$ intakes appeared to be the total amount of food ingested, which is strongly correlated with both $\mathrm{Na}$ and $\mathrm{K}$ intakes. The latter correlation has been described in our study as well as in other populations with energy intake as a surrogate measure of food intake $\mathrm{i}^{(33,34)}$.

\section{Strengths and limitations}

Although willingness to participate leads to some selection bias, the current data represent a more general population of pre-school children in Flanders compared with other food consumption surveys which have mostly been restricted to local areas. Nevertheless, as shown 
previously in our design paper ${ }^{(14)}$, the study sample was subject to some selection bias, with lower socio-economic classes being under-represented.

As mentioned before, only $66 \%$ of the collected diaries included three completed record days and could therefore be used for statistical analyses. Many factors typical among pre-school children (e.g. illiteracy and short memory) make assessing diet intake in this young population very difficult. The most important barriers for measuring dietary intake in pre-school children are the fact that they are not able to complete diaries on their own and that they have a limited cognitive ability to recall, estimate and otherwise cooperate; and they often spend time under the care of several individuals ${ }^{(35,36)}$. Therefore it is always a challenge to assess dietary intakes in children of pre-school age and an important loss/lack of information is common in many surveys which often leads to the exclusion of extra participants ${ }^{(37)}$.

It is also noteworthy that like any dietary assessment methodology, diet records are prone to a degree of misreporting and this may have influenced our classification of compliance and non-compliance with DRI. The percentage of under-reporters in the final sample for analysis was low $(<2 \%)$. In addition, a $3 \mathrm{~d}$ diet record does not necessarily reflect an individual's usual intake. However, a statistical modelling method (the Nusser method) that accounts for within-individual variability was used in order to calculate usual $\mathrm{Na}$ and $\mathrm{K}$ intakes. Since all days of the week were included in the study, it was possible to adjust our data to remove the effect of the day of the week. Unfortunately, it was impossible to correct for seasonal variations, because the fieldwork was conducted only during autumn and winter. No data were found about potential seasonal influences on nutrient intake in this population group in Belgium. However, from our national food consumption survey in 2004 it could be concluded that seasonal variations were only small for nutrient intakes ${ }^{(38)}$. These low seasonal variations could be due to the widespread availability of most foods all year round.

The underestimation of $\mathrm{Na}$ intake due to the nonassessment of discretionary salt use and the potential bias of dietary records for evaluating the actual intake were less critical for the present analysis whose main objective was to assess the dietary sources and correlates, rather than the absolute intake values of $\mathrm{Na}$ and $\mathrm{K}$. Despite these limitations, the reported contributions of $\mathrm{Na}$ and $\mathrm{K}$ intakes in Flemish pre-school children are very similar to the values described in other industrialized populations ${ }^{(6,26,39-41)}$. Nevertheless it should be noted that the under-representation of low-SES families could have biased our results and might be hiding a possible relationship between SES and $\mathrm{Na}$ intake. In addition, the difference in Na intake between lowand high-SES groups might be due to differences in table salt which was not included in our analyses ${ }^{(42)}$.

Another potential problem encountered was that the Estimated Average Requirement (EAR) values for pre-school children are still lacking for the nutrients under study, which made it difficult to establish inadequacy. However, when comparing $\mathrm{K}$ intakes obtained from our pre-school population with the AI values for $\mathrm{K}$ intake, it is still possible to say that the intakes of our pre-school children are adequate when the intake is above the $\mathrm{AI}(<15 \%$ of our Flemish pre-school children had an intake above the IOM's AI of $3000 \mathrm{mg} / \mathrm{d})^{(43)}$.

Finally, it should be noted that the food composition data used for calculating nutrient intakes might also introduce some bias in dietary surveys reporting such data. Therefore, the authors would like to emphasize the growing requirement for good food composition data. In addition, it remains important to consider other dietary intake recommendations as well when developing guidelines to reduce the $\mathrm{Na}: \mathrm{K}$ intake ratio among children.

\section{Recommendations}

From the results derived in the present study, the comparison with the literature and the knowledge that the reported $\mathrm{Na}$ intakes are an underestimation of the true intakes as discretionary salt was not included in the analyses, it is clear that unfavourably high $\mathrm{Na}$ intakes remain prevalent even among childhood populations. In addition it seems that $\mathrm{K}$ intakes, which presumably could compensate for the harmful effects of high $\mathrm{Na}$ intakes, are too low in childhood populations. Although higher $\mathrm{K}$ intakes could be obtained via dietary guidelines stimulating the consumption of fruit and vegetables and low-fat milk among children, a recent review from Brown and colleagues demonstrates the obstacles in reducing salt intake in different populations ${ }^{(44)}$. An important barrier is the high $\mathrm{Na}$ content of manufactured/industrial food products and food catering ${ }^{(44)}$. Even some types of water can have high $\mathrm{Na}$ contents (higher than $20 \mathrm{mg} / \mathrm{l}$, with a maximum of $119 \mathrm{mg} / \mathrm{l}$ for Gerolsteiner). Therefore, public health initiatives, in tandem with efforts by the food industry, are urgently needed to lower salt consumption and consequently lower CVD burden and increase life expectancy ${ }^{(44)}$.

In Finland for instance, a comprehensive public health campaign in collaboration with the food industry to reduce CVD resulted in remarkable reductions in salt intake over a 20-year period, which coincided with a decrease of $60 \%$ in both CHD and stroke mortality ${ }^{(45)}$.

\section{Conclusions}

In summary, in Flemish pre-school children surveyed in 2002 and 2003, mean $\mathrm{Na}$ intake largely exceeded, whereas mean $\mathrm{K}$ intake was well below, that recommended. This situation could be improved by promoting the consumption of food categories with a low Na:K ratio such as fruits, vegetables and dairy products. Although some food groups that importantly contribute to pre-school children's daily $\mathrm{Na}$ intakes (e.g. cheeses, meat products and 
savoury snacks) could be discouraged, it is important to consider other nutrient requirements as well (e.g. contribution to water and vegetable intakes of soup and to fibre intake of bread). It is noteworthy that a decrease in the consumption of cheese should be compensated by an increase of alternative Ca sources that contribute less to the total $\mathrm{Na}$ intake (e.g. milk) in order to guarantee sufficient $\mathrm{Ca}$ intakes.

\section{Acknowledgements}

The Flanders pre-school dietary survey was funded by the Belgian Nutrition Information Center (NICE). C.V. is postdoctoral researcher funded by the FWO-Flanders. The authors declare no conflict of interest. I.H. performed and interpreted statistical analyses and drafted the article. M.B. and M.D.M., the dietitians of the team, were responsible for the data input and contributed to the conceptualization of the FFQ. All other authors helped in the evaluation of the results and the writing of the manuscript. Moreover, I.H. and S.D.H. were responsible for the study protocol and the fieldwork. All authors have read and have approved the manuscript as submitted. We thank all the parents and teachers who participated in this project and generously volunteered their time and knowledge.

\section{References}

1. Institute of Medicine (2004) Dietary Reference Intakes for Water, Potassium, Sodium, Chloride, and Sulfate. Washington, DC: National Academy of Sciences.

2. Meneton P, Jeunemaitre X, de Wardener HE et al. (2005) Links between dietary salt intake, renal salt handling, blood pressure, and cardiovascular diseases. Physiol Rev 85, 679-715.

3. Cook NR, Obarzanek E, Cutler JA et al. (2009) Joint effects of sodium and potassium intake on subsequent cardiovascular disease: the trials of Hypertension Prevention Followup Study. Arch Intern Med 169, 32-40.

4. Tsugane S \& Sasazuki S (2007) Diet and the risk of gastric cancer: review of epidemiological evidence. Gastric Cancer 10, 75-83.

5. He FJ \& MacGregor GA (2002) Effect of modest salt reduction on blood pressure: a meta-analysis of randomized trials. Implications for public health. J Hum Hypertens 16, $761-770$.

6. He FJ, Marrero NM \& MacGregor GA (2008) Salt and blood pressure in children and adolescents. J Hum Hypertens 22 , 4-11.

7. Appel LJ, Giles TD, Black HR et al. (2010) ASH position paper: dietary approaches to lower blood pressure. $J$ Am Soc Hypertens 4, 79-89.

8. Wang Y, Bentley ME, Zhai F et al. (2002) Tracking of dietary intake patterns of Chinese from childhood to adolescence over a six-year follow-up period. J Nutr 132, 430-438.

9. Jones G, Riley MD \& Whiting S (2001) Association between urinary potassium, urinary sodium, current diet, and bone density in prepubertal children. Am J Clin Nutr 73, 839-844.

10. Elliott P, Dyer A \& Stamler R (1989) The INTERSALT study: results for 24 hour sodium and potassium, by age and sex. INTERSALT Co-operative Research Group. J Hum Hypertens 3, 323-330.
11. Geleijnse JM, Grobbee DE \& Hofman A (1990) Sodium and potassium intake and blood pressure change in childhood. BMJ 300, 899-902.

12. He FJ \& MacGregor GA (2003) Potassium: more beneficial effects. Climacteric 6, Suppl. 3, 36-48.

13. Huybrechts I \& De Henauw S (2007) Energy and nutrient intakes by pre-school children in Flanders-Belgium. $\mathrm{Br} \mathrm{J}$ Nutr 98, 600-610.

14. Huybrechts I, Matthys C, Pynaert I et al. (2008) Flanders preschool dietary survey: rationale, aims, design, methodology and population characteristics. Arch Public Health 66, 5-25.

15. Goldberg GR, Black AE, Jebb SA et al. (1991) Critical evaluation of energy intake data using fundamental principles of energy physiology: 1 . Derivation of cut-off limits to identify under-recording. Eur J Clin Nutr 45, 569-581.

16. NUBEL (2004) Belgian Food Composition Table, 4th ed. Brussels: Ministry of Public Health.

17. NEVO (2001) NEVO-Table, Dutch Food Composition Table 2001. Zeist: NEVO Foundation.

18. Institut Paul Lambin (2004) Table de Composition des Aliments 2004. Bruxelles: IPL.

19. Food Standards Agency (2002) McCance and Widdowson's The Compostition of Foods. Cambridge: Royal Society of Chemistry.

20. Iowa State University (2006) C-SIDE. http://www.cssm. iastate.edu/software/cside.html (accessed September 2011).

21. Institute of Medicine (2003) Dietary Reference Intakes: Applications in Dietary Assessment. Washington, DC: National Academy Press.

22. Krebs-Smith SM, Kott PS \& Guenther PM (1989) Mean proportion and population proportion: two answers to the same question? J Am Diet Assoc 89, 671-676.

23. Allison ME \& Walker V (1986) The sodium and potassium intake of 3 to 5 year olds. Arch Dis Child 61, 159-163.

24. Arbeit ML, Nicklas TA \& Berenson GS (1992) Considerations of dietary sodium/potassium/energy ratios of selected foods. J Am Coll Nutr 11, 210-222.

25. Beer-Borst S, Costanza MC, Pechere-Bertschi A et al. (2009) Twelve-year trends and correlates of dietary salt intakes for the general adult population of Geneva, Switzerland. Eur J Clin Nutr 63, 155-164.

26. Meneton P, Lafay L, Tard A et al. (2009) Dietary sources and correlates of sodium and potassium intakes in the French general population. Eur J Clin Nutr 63, 1169-1175.

27. Witschi JC, Capper AL, Hosmer DW Jr et al. (1987) Sources of sodium, potassium, and energy in the diets of adolescents. J Am Diet Assoc 87, 1651-1655.

28. Gerber AM, James SA, Ammerman AS et al. (1991) Socioeconomic status and electrolyte intake in black adults: the Pitt County Study. Am J Public Health 81, 1608-1612.

29. Belle M, Hanss M, Guillaumont M et al. (1991) Des-gammacarboxyprothrombin detection by immunoblotting after polyacrylamide gel affinoelectrophoresis in human plasmas. Electrophoresis 12, 294-297.

30. Ganguli MC, Grimm RH Jr, Svendsen KH et al. (1997) Higher education and income are related to a better Na:K ratio in blacks: baseline results of the Treatment of Mild Hypertension Study (TOMHS) data. Am J Hypertens 10, 979-984.

31. Hajjar I \& Kotchen T (2003) Regional variations of blood pressure in the United States are associated with regional variations in dietary intakes: the NHANES-III data. J Nutr 133, 211-214.

32. Kodama N, Morikuni E, Matsuzaki N et al. (2005) Sodium and potassium balances in Japanese young adults. $J$ Nutr Sci Vitaminol (Tokyo) 51, 161-168.

33. Pietinen P (1982) Estimating sodium intake from food consumption data. Ann Nutr Metab 26, 90-99.

34. Brion MJ, Ness AR, Davey SG et al. (2008) Sodium intake in infancy and blood pressure at 7 years: findings from the 
Avon Longitudinal Study of Parents and Children. Eur J Clin Nutr 62, 1162-1169.

35. Stein AD, Shea S, Basch CE et al. (1991) Variability and tracking of nutrient intakes of preschool children based on multiple administrations of the 24-hour dietary recall. Am J Epidemiol 134, 1427-1437.

36. Stein AD, Shea S, Basch CE et al. (1992) Consistency of the Willett semiquantitative food frequency questionnaire and 24-hour dietary recalls in estimating nutrient intakes of preschool children. Am J Epidemiol 135, 667-677.

37. Livingstone MB \& Robson PJ (2000) Measurement of dietary intake in children. Proc Nutr Soc 59, 279-293.

38. De Vriese S, Huybrechts I, Moreau M et al. (2006) Enquête de consommation alimentaire Belge 1 - 2004: Rapport (The Belgian Food Consumption Survey 1 - 2004: Report). D/2006/2505/16. Brussels: Scientific Institute of Public Health.

39. Maldonado-Martin A, Garcia-Matarin L, Gil-Extremera B et al. (2002) Blood pressure and urinary excretion of electrolytes in Spanish schoolchildren. J Hum Hypertens 16, 473-478.
40. Ervin RB, Wang CY, Wright JD et al. (2004) Dietary intake of selected minerals for the United States population: 1999-2000. Adv Data issue 341, 1-5.

41. Heird WC, Ziegler P, Reidy K et al. (2006) Current electrolyte intakes of infants and toddlers. J Am Diet Assoc 106, 1 Suppl. 1, S43-S51.

42. Grimes CA, Campbell KJ, Riddell LJ et al. (2011) Sources of sodium in Australian children's diets and the effect of the application of sodium targets to food products to reduce sodium intake. Br J Nutr 105, 468-477.

43. Prentice A, Branca F, Decsi T et al. (2004) Energy and nutrient dietary reference values for children in Europe: methodological approaches and current nutritional recommendations. Br J Nutr 92, Suppl. 2, S83-S146.

44. Brown IJ, Tzoulaki I, Candeias V et al. (2009) Salt intakes around the world: implications for public health. Int $J$ Epidemiol 38, 791-813.

45. Laatikainen T (2006) Sodium in the Finnish diet: 20-year trends in urinary sodium excretion among the adult population. Eur J Clin Nutr 60, 965-970. 